\title{
New components of the necroptotic pathway
}

\author{
Zhenru Zhou, Victor Han, Jiahuai Han ${ }^{\square}$ \\ State Key Laboratory of Cellular Stress Biology and School of Life Sciences, Xiamen University, Xiamen 361005, China \\ $\triangle$ Correspondence: jhan@xmu.edu.cn \\ Received August 16, 2012 Accepted September 19, 2012
}

\begin{abstract}
Programmed necrosis, also known as necroptosis, has recently drawn great attention. As an important cellular regulation mechanism, knowledge of its signaling components is expanding. Necroptosisis demonstrated to be regulated by the RIP1 and RIP3 kinases, and its pathophysiological importance has been confirmed in a number of disease models. Here we review the new members of this necroptosis pathway, MLKL, PGAM5, Drp1 and DAl, and discuss some of their possible applications according to recent findings.
\end{abstract}

\section{KEYWORDS necrosis, necroptosis, necrosome}

\section{INTRODUCTION}

Necrosis is a type of cell death morphologically characterized by cell rounding, cell volume increase, organelle swelling, and the bursting of the cytoplasmic membrane (Laster et al., 1988). Necrosis is different from apoptosis not only in its morphologic definition, but also in the general belief that it is an unregulated cell death. However, evidence that the receptor-interacting protein kinase 1 (RIP1) and RIP3-regulated cell deaths possess necrotic phenotypes completely changes this misconception (Cho et al., 2009; He et al., 2009; Zhang et al., 2009). Based on the convention that special names, such as anoikis, entosis, and pyroptosis etc. (Galluzzi et al., 2012), are used for different types of cell deaths, "necroptosis" has recently been used for programmed necrosis (Galluzzi et al., 2012) despite the fact that it was originally used to describe only RIP1-dependent necrosis (Degterev et al., 2005).

Much of our understanding of necroptosis has been formed by studying tumor necrosis factor (TNF)-induced necroptotic cell death (Vandenabeele et al., 2010) (Fig. 1). Upon TNF and TNF receptor 1 (TNFR1) ligation, TNFR1 recruits TNFR-associated death domain (TRADD), receptor-interac- ting protein 1 (RIP1), and TNFR-associated factor 2 (TRAF2) (Harper et al., 2003; Micheau and Tschopp, 2003).TRAF2 then binds to cellular inhibitor of apoptosis proteins 1 and 2 (cIAP1/2), allowing for the recruitment of the linear ubiquitin chain assembly complex (LUBAC), which acts as a scaffold to recruit the TAB-transforming growth factor-activated kinase 1 (TAK1) complex and IKB kinase (IKK) subunit NEMO to form TNFR1 complex 1 (Ea et al., 2006; Wu et al., 2006; Bertrand et al., 2008; Haas et al., 2009). After deubiquitination by cylindromatosis (CYLD) (Wright et al., 2007), RIP1 recruits TRADD, the Fas-associated protein with a death domain (FADD) and caspase-8 combine to form TNFR1 complex II (Micheau and Tschopp, 2003; Wang et al., 2008; Cho et al., 2009), which mediates apoptosis. When RIP3 is present, it can incorporate itself into complex II to form complex Ilb (also called necrosome), containing FADD, caspase 8, RIP1, and RIP3 (Holler et al., 2000; Cho et al., 2009). Both an inhibition of caspase 8 and increase in RIP3 can promote the activity of the necrosome and result in necroptosis (Vercammen et al., 1998a; Zhang et al., 2009; Oberst et al., 2011). Because both a dominant negative FADD expression and FADD depletion promote necroptosis, FADD appears to inhibit the necrosome (Galluzzi et al., 2011). The deubiquitinating enzyme CYLD has been shown to promote necroptosis in intestine epithelial cells, most likely by deubiquitinating RIP1 (Welz et al., 2011). However, ubiquitin editing enzyme A20 negatively regulates necroptosis (Vanlangenakker et al., 2011a). Other signaling molecules that promote NF-kB activation, such as TAK1 and clAP1, also negatively regulate necroptosis (Vanlangenakker et al., 2011a, 2011b).

The necroptotic and apoptotic pathways can compete against each other since both the inactivation of the necrosome by the caspase 8-mediated RIP3 cleavage and the conversion of apoptosis to necroptosis by RIP3 upregulation have been reported (Zhang et al., 2009; Han et al., 2011; Oberst et al., 2011). FLICE-like inhibitor protein long (CFLIPL) binds with caspase 8 in the resting stage, and the basal activity of caspase 8 is believed to be responsible for the inac- 


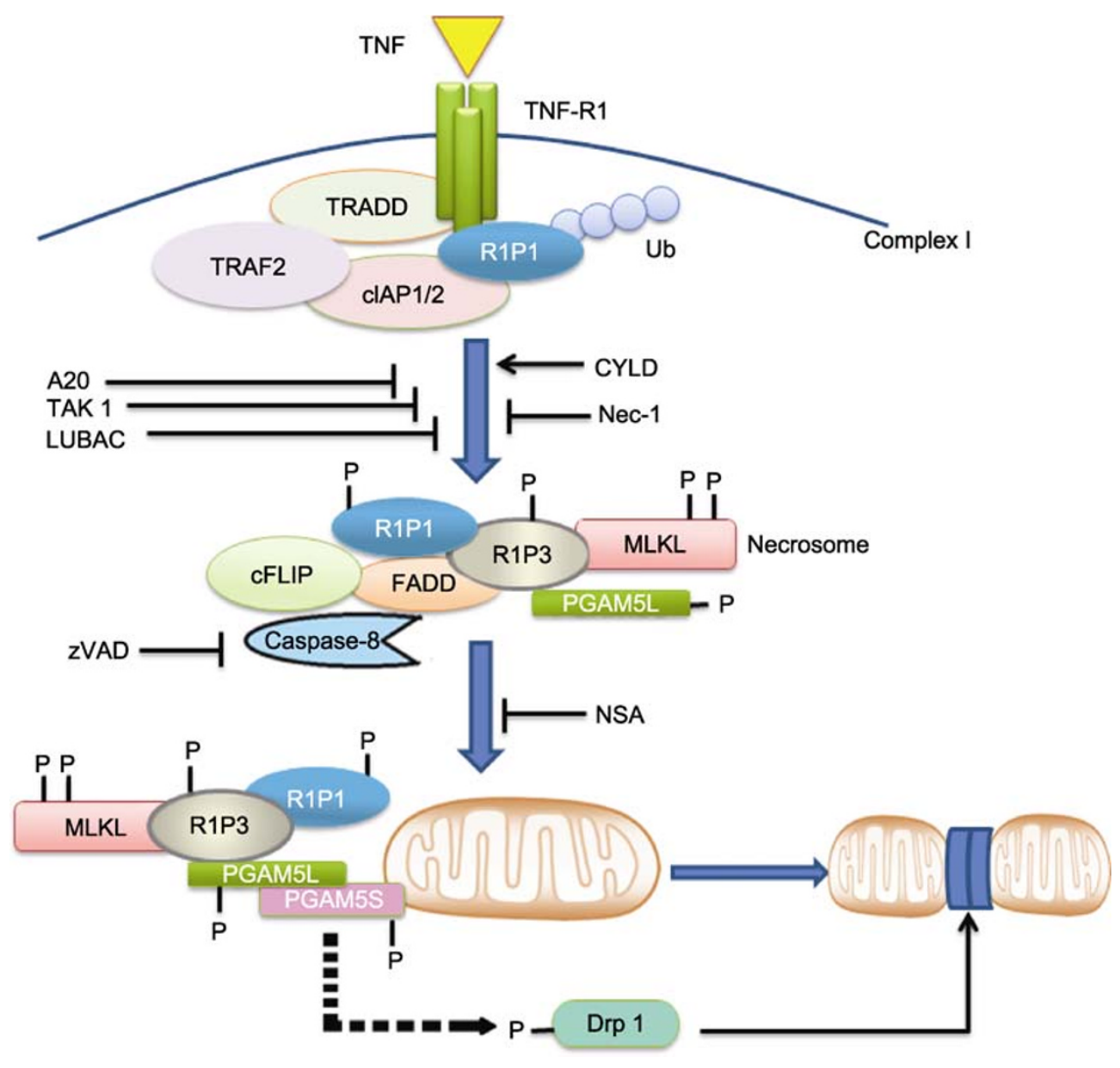

Figure 1. TNF-induced programmed necrosis pathway. Upon TNF induction, TNF receptor 1 recruits TRADD, RIP1, TRAF2 and clAP1/2 to form TNFR1 complex I. Within this complex, A20, an ubiquitin-editing enzyme, LUBAC, a linear ubiquitylating enzyme complex, and TAK1 negatively regulate TNF-induced programmed necrosis. Necrostatin-1 blocks necroptosis by targeting RIP1 kinases. The deubiquitination of RIP1 by CYLD and the inhibition of caspase-8 are critical for the assembly of necrosome. Within the necrosome, the apoptosis machinery FADD, cFLIP, and caspase-8 suppress the induction of necroptosis. The kinase activities of RIP1 and RIP3 are necessary for necrosome formation. After RIP3 is phosphorylated, it phosphorylates MLKL and PGAM5L, and then engages PGAM5S on the mitochondrial membrane, during which the engagement is inhibited by NSA. Once activated, PGAM5L/PGAM5S then activate the mitochondrial fission regulator Drp1 by dephosphorylation, thus leading to mitochondrial fission.

tivation of the RIP1/RIP3 necrosome (Kaiser et al., 2011; Oberst et al., 2011; Zhang et al., 2011). However, it's currently unknown how RIP3 suppresses the apoptosis pathway. Necroptosis also functions as a backup for apoptosis (Vercammen et al., 1998a; Holler et al., 2000; Han et al., 2011; Kaiser et al., 2011; Oberst et al., 2011; Welz et al., 2011; Zhang et al., 2011). For example, in the absence of caspase 8 , the death of T cells isnot blocked, but uses a necroptosis pathway instead (Salmena and Hakem, 2005; Ch'en et al., 2011).

The increasing attention on necroptosis is largely due to recent findings on its pathological and physiological importance. RIP1 kinase activity contributes to ischemic brain injury (Degterev et al., 2005; Northington et al., 2011) and myocardial ischemia-reperfusion injury (Smith et al., 2007;
Oerlemans et al., 2012). RIP3-mediated necroptosis is proven to be involved in pancreatitis (He et al., 2009), photoreceptor cell loss (Trichonas et al., 2010), skin inflammation (Bonnet et al., 2011), and defense mechanisms against some virus infections, such as the vaccinia virus (He et al., 2009) and the murine cytomegalovirus (Upton et al., 2010). Necroptosis also participates in the host defense against Salmonella Typhimurium infections (Robinson et al., 2012). One developmental role of necroptosis is demonstrated by rescuing the embryonic lethality of FADD deficient mice with RIP1knockout, or Caspase 8 knockout withRIP3 gene deletion (Kaiser et al., 2011; Zhang et al., 2011). In addition, necroptosis is demonstrated to take part in lymphoproliferative disease (Ch'en et al., 2011; Kaiser et al., 2011), Crohn's 
disease (Gunther et al., 2011; Welz et al., 2011) and acute liver injury (Liedtke et al., 2011).

Despite great progress in the past few years in the understanding the molecular mechanisms of programmed necrosis, necroptosis is still a new field in cell death study. Since a number of excellent reviews in the past couple of years have already summarized the basic RIP1/RIP3 necrosis pathway information, we briefly review the RIP1/RIP3 complexes and then focus on the recently identified components of the necroptosis pathway.

\section{CURRENT INSIGHT INTO THE RIP1/RIP3 SIGNALING COMPLEX}

RIP1 and RIP3 play a central role in TNF-induced necroptosis (Cho et al., 2009; He et al., 2009; Zhang et al., 2009). Like the formation of complex II in apoptotic processes, necrosome formation appears to be facilitated by the deubiquitination of RIP1 (O'Donnell et al., 2011; Vanlangenakker et al., 2011b). While it is clear that the RIP1/RIP3 complex is the core of the necrosome, the formation and function mechanisms of the necrosome are still largely unknown. Necrosomes are large protein complexes with an estimated molecular weight of over $5 \mathrm{MDa}$ (Feoktistova et al., 2011; Tenev et al., 2011). In addition to RIP1 and RIP3, the necrosome contains many other components and could be heterogeneous (Han et al., 2011). Recent studies have shown that RIP1 and RIP3 form an oligomeric amyloid signaling complex (Li et al., 2012), which could be the backbone of the large necrosome complex. RIP homotypic interaction motif (RHIM), found in both RIP1 and RIP3, is a key structure domain in both that mediates the formation of the amyloid complex. The scaffolds of amyloids may function as a crucial platform for recruiting other components, such as MLKL, and stimulating the downstream execution mechanisms of necroptosis (Li et al., 2012). Amyloid fibers, oligomers and aggregates can be found in various diseases, including Alzheimer's. Since prion-like amyloid aggregation itself can be cytotoxic, it would be very interesting to know if the cell can sense an amyloid-like necrosome as a dangerous signal or if it can initiate a specific signal for cell death.

\section{MLKL AS A NECESSARY COMPONENT FOR NECROSOME FUNCTION}

By screening a chemical library, Xiaodong Wang's group found that necrosulfonamide ((E)-N-(4-(N-(3-methoxypyrazin-2-yl) sulfamoyl) phenyl)-3-(5-nitrothiophene-2-yl) acrylamide), referred to as NSA, can effectively block TNF-induced necroptosis in human cells. They further identified the mixed lineage kinase domain-like protein (MLKL) as a target of this compound (Sun et al., 2012). MLKL was also identified in the immunoprecipitation of RIP3, demonstrating that it interacts with RIP3 and is thus a component of the necrosome (Fig. 1).
The importance of MLKL in necroptosisis also supported in later work by another group who identified it as a required molecule for TNF-induced necroptosis in a screening of a kinase/phosphatase shRNA library in human colon adenocarcinoma HT-29 cells (Zhao et al., 2012).

Similar to the effects of RIP3 knockdown on necroptosis, the knockdown of MLKL blocked cell death, showing that MLKL is required for TNF-induced necroptosis (Sun et al., 2012). To interact with MLKL, RIP3 needs to be phosphorylated at Ser227. The phosphorylation at Ser227 is likely to be autophosphorylation since it occurs when RIP3 is over-expressed and abolished in a kinase dead RIP3 mutant (Sun et al., 2012). In response to necroptosis induction, RIP3 phosphorylates MLKL at Thr357 and Ser358. Neither position's phosphorylation is sufficient for necroptosis, but both are required for necroptosis. Mutations at Thr357 and Ser358 do not affect the interaction between MLKL and RIP3, but has a dominant negative effect on the function of MLKL. In mice, Thr357 becomes an asparagine, while Ser358 is conserved. The regions around Ser227 in RIP3 and Thr357/Ser358 in MLKL are not conserved in humans and mice, which could be the reason for the undetectable interaction between murine RIP3 and human MLKL. Nevertheless, murine RIP3 interacts with murine MLKL, indicating that the functional relationship between RIP3 and MLKL is conserved in mammals.

The phosphorylations of MLKL at Thr357 and Ser358 have been proposed to be markers of necrosome activation because while a non-phosphorylated MLKL mutant can be incorporated into the necrosome, the phosphorylation of the two sites is required for cell death (Sun et al., 2012). Downstream necrosome activation events could be a sustained JNK activation and ROS generation (Zhao et al., 2012), but considering that the requirements of prolonged JNK activation and ROS induction are tissue and cell-type specific (He et al., 2009; Fortes et al., 2012), the other downstream events of MLKL could be more critical to programmed necrosis.

\section{DEPHOSPHORYLATION OF DrP1 BY PGAM5 AS A POTENTIAL CONVERGENT POINT OF DIFFERENT NECROTIC PATHWAYS}

By separating and analyzing cell extracts containing RIP3, PGAM5, a mitochondrial phosphoglyceratemutase was identified to be another necrosome associated protein by Xiaodong Wang's group (Takeda et al., 2009; Wang et al., 2012). It was reported earlier that PGAM5 can use an alternative Ser/Thr phosphatase activity to dephosphorylate ASK1 (Takeda et al., 2009). Dynamin-related protein 1 (Drp1), a regulator of mitochondrial fission, could be regulated by PGAM5 through the dephosphorylation of Drp1 (Wang et al., 2012). Since mitochondrial fragmentation was observed during necroptosis, a model was proposed where PGAM5 promotes mitochondrial fission and subsequently cellular necroptosis through the dephosphorylation of Drp1 (Fig. 1). 
Notably, the two variants of PGAM5, PGAM5S and PGAM5L, function differently during necroptosis, even though they are both required for necroptosis execution. After the core part of necrosome is formed, PGAM5L binds to the necrosome, unaffected by the necroptosis inhibitor NSA; the binding of PGAM5S, however, is blocked by NSA. What makes PGAM5 more interesting is that PGAM5S and PGAM5L are both required for intrinsic necroptosis induced by $\mathrm{H}_{2} \mathrm{O}_{2}$ or $\mathrm{A} 23187$. RIP1, RIP3, and MLKL, on the other hand, only affect extrinsic pathways induced by TNF- $\alpha$ and other extracellular ligands. Even though the ubiquitous involvement of PGAM5 needs more evidence, PGAM5 could fill the gap that is preventing investigators from studying the common execution mechanisms for different forms of necrosis. It needs to be noted, though, that the role of mitochondrial fission in apoptosis is not clear since both supporting and opposing data have been reported (Frank et al., 2001; Lee et al., 2004; Germain et al., 2005; Parone et al., 2006; Brooks et al., 2007; Estaquier and Arnoult, 2007; Sheridan et al., 2008). Whether the role of mitochondrial fragmentation is a cause or consequence of necrosis may need more investigation.

\section{DAI AS A NEW PARTNER OF RIP3 TO FIGHT AGAINST VIRUSES}

Cellular necroptosis can be induced by some viral infections (Benedict et al., 2002). Cho et al showed that RIP3 was used to mediate vaccinia virus-induced necroptosis when cellular apoptosis machinery was inhibited (Cho et al., 2009). Murine cytomegalovirus (MCMV) infection induces a form of necroptosis that was shown to be RIP3-dependent by Upton et al (2010). While MCMV-induced cell death is controlled by RIP3 kinase activity and RHIM-dependent interactions, it does not depend on RIP1 or TRIF, two RHIM-containing members involved in regulated necrosis. Further studies have revealed that the DNA-dependent activator of IRF (DAI, also known as ZBP-1 or DLM-1), a RHIM domain containing protein and a potential DNA sensor, is the essential partner of RIP3 during MCMV infection induced necroptotic cell death (Upton et al., 2012).

DAI was first identified as a cytoplasmic DNA sensor capable of inducing type 1 interferon production (Takaoka et al., 2007), but was re-examined when $\mathrm{DAl}^{--}$mice showed the normal phenotype in both innate and adaptive immune responses to B-DNA and DNA vaccines (Ishii et al., 2008). While it's questionable whether DAI isa DNA sensor for an anti-viral IFN response, virus-induced DAI-RIP3 complexes indicate that it could be a type of specialized sensor that is responsible for necroptosis, but not for type I interferon response.

\section{CHEMICAL INHIBITORS OF PROGRAMMED NECROSIS}

Small molecule compounds that inhibit programmed necrosis are not only effective tools in the study of necrotic cell deaths, but also have potential to become pro-drugs for developing treatments for necroptosis-related human diseases. Necrostatin-1 is the first necroptosis inhibitor to have been widely used in vitro or in animal models to study necroptosis. It was screened out from a small compound library as an inhibitor of necroptosis (Degterev et al., 2005). Based on structure modeling and prediction, necrostain-1 is believed to be a RIP1 inhibitor (Degterev et al., 2008). Although it is a RIP1 inhibitor, necrostain-1 does not inhibit RIP1-mediated apoptosis, which is believed to be due to the fact that necrostain-1 does not inhibit RIP1 kinase activity (Han et al., 2009). The inhibition of necroptosis by necrostain- 1 is at least partly due to its inhibition of the association between RIP1 and RIP3 (Degterev et al., 2008; He et al., 2009). The application of necrostain-1 in mice disease models has been proven to be a very useful experimental approach and has provided much valuable information on the role of necroptosis in pathological conditions (Trichonas et al., 2010; Fortes et al., 2012). Currently, there is no RIP3 inhibitor available. Given the fact that RIP3 is involved in necroptosis but not apoptosis, a RIP3 inhibitor could be a more selective drug for necroptosis.

As is mentioned above, NSA was screened out to block necroptosis downstream of RIP3 activation (Sun et al., 2012). Biotin-NSA/streptavidin-conjugated beads pull down and structure-activity relationship (SAR) studies reveal that NSA targets the N-terminal fragment of MLKL and covalently modifies MLKL through a chemical reaction called a Michael addition at a reactive amino acid residue cysteine. NSA targets human MLKL but not mouse MLKL, so NSA cannot be used in animal models, but NSA could become a pro-drug for clinical applications in treating necrosis related human diseases.

\section{PERSPECTIVES}

Evidence suggests that necroptosis is a tightly regulated process important in various physiological and pathological conditions (Han et al., 2011; Vanlangenakker et al., 2012). Our understanding of the necroptosis pathway is still in its infant stage, compared to that of apoptosis,. The most unclear part of necroptosis is how it is executed. To date, we still lack a biomarker for the in vivo detection of necroptosis. It is known that mitochondria play an important role in both apoptosis and necroptosis, and that $\mathrm{Bcl}-2$ family proteins also have similar pro- and anti-roles for apoptosis and necroptosis (Tsujimoto et al., 1997; Kroemer et al., 1998; Meilhac et al., 1999; Irrinki et al., 2011), but how Bcl-2 family members function in influencing apoptosis and necroptosis is unclear. Mitochondrial membrane permeability transition pore opening is believed to be involved in both apoptotic and necroptotic cell death, and the pore component cyclophilin $D$ was reported to be required for necroptosis (Nakagawa et al., 2005; Tsujimoto and Shimizu, 2007; Devalaraja-Narashimha et al., 
2009). However, there is still no data suggesting the involvement of cyclophilin D in RIP3-mediated necroptosis. It is highly possible that multiple necrosis pathways operate at the mitochondrial level. As more stimuli, including those via intrinsic pathways and extrinsic pathways, are discovered to trigger necrosis, RIP1/RIP3 dependent necrosis may be only one of many important necrotic pathways (Vercammen et al., 1998b; Petit et al., 2002; Meurette et al., 2007; JouanLanhouet et al., 2012). In addition to mitochondrial ROS, mitochondrial fission and sustained JNK activation, the phosphorylation of STAT3 on Ser727 and the interaction between STAT3 and GRIM-19, a subunit of mitochondrial complex I, was found during necroptosis (Shulga and Pastorino, 2012). Finding the convergent point and the common executing mechanism of the different pathways of necrosis is still a challenge. Further understanding of the mechanisms of programmed necrosis should have a significant impact on the development of therapeutic intervention of many necrosis-related human diseases.

\section{ACKNOWLEDGEMENTS}

This work was supported by the National Basic Research Program (973 Program) (No. 2009CB522200), National Natural Science Foundation of China (Grant Nos. 91029304, 30830092, 30921005 and 81061160512), and 111 Project B12001.

\section{ABBREVIATIONS}

cFLIPL, FLICE-like inhibitor protein long; cIAP, cellular inhibitor of apoptosis protein; CYLD, cylindromatosis; Drp1, Dynamin-related protein 1; FADD, Fas-associated protein with a death domain; IKK, IKB kinase; LUBAC, linear ubiquitin chain assembly complex; MCMV, murine cytomegalovirus; MLKL, mixed lineage kinase domain-like protein; RIP, receptor-interacting protein; RHIM, RIP homotypic interaction motif; SAR, structure-activity relationship; TAK, growth factor-activated kinase; TNF, tumor necrosis factor; TNFR, TNF receptor; TRADD, TNFR-associated death domain; TRAF, TNFR-associated factor

\section{REFERENCES}

Benedict, C.A., Norris, P.S., and Ware, C.F. (2002). To kill or be killed: viral evasion of apoptosis. Nat Immunol 3, 1013-1018.

Bertrand, M.J., Milutinovic, S., Dickson, K.M., Ho, W.C., Boudreault, A., Durkin, J., Gillard, J.W., Jaquith, J.B., Morris, S.J., and Barker, P.A. (2008). clAP1 and clAP2 facilitate cancer cell survival by functioning as E3 ligases that promote RIP1 ubiquitination. Mol Cell 30, 689-700.

Bonnet, M.C., Preukschat, D., Welz, P.S., van Loo, G., Ermolaeva, M.A., Bloch, W., Haase, I., and Pasparakis, M. (2011). The adaptor protein FADD protects epidermal keratinocytes from necroptosis in vivo and prevents skin inflammation. Immunity 35 , 572-582.

Brooks, C., Wei, Q., Feng, L., Dong, G., Tao, Y., Mei, L., Xie, Z.J., and Dong, Z. (2007). Bak regulates mitochondrial morphology and pathology during apoptosis by interacting with mitofusins. Proc Natl Acad Sci U S A 104, 11649-11654.

Ch'en, I.L., Tsau, J.S., Molkentin, J.D., Komatsu, M., and Hedrick, S.M. (2011). Mechanisms of necroptosis in T cells. J Exp Med 208, 633-641.

Cho, Y.S., Challa, S., Moquin, D., Genga, R., Ray, T.D., Guildford, M., and Chan, F.K. (2009). Phosphorylation-driven assembly of the RIP1-RIP3 complex regulates programmed necrosis and virus-induced inflammation. Cell 137, 1112-1123.

Degterev, A., Hitomi, J., Germscheid, M., Ch'en, I.L., Korkina, O., Teng, X., Abbott, D., Cuny, G.D., Yuan, C., Wagner, G., et al. (2008). Identification of RIP1 kinase as a specific cellular target of necrostatins. Nat Chem Biol 4, 313-321.

Degterev, A., Huang, Z., Boyce, M., Li, Y., Jagtap, P., Mizushima, N., Cuny, G.D., Mitchison, T.J., Moskowitz, M.A., and Yuan, J. (2005). Chemical inhibitor of nonapoptotic cell death with therapeutic potential for ischemic brain injury. Nat Chem Biol 1, 112-119.

Devalaraja-Narashimha, K., Diener, A.M., and Padanilam, B.J. (2009). Cyclophilin D gene ablation protects mice from ischemic renal injury. Am J Physiol Renal Physiol 297, F749-759.

Ea, C.K., Deng, L., Xia, Z.P., Pineda, G., and Chen, Z.J. (2006). Activation of IKK by TNFalpha requires site-specific ubiquitination of RIP1 and polyubiquitin binding by NEMO. Mol Cell 22, 245-257.

Estaquier, J., and Arnoult, D. (2007). Inhibiting Drp1-mediated mitochondrial fission selectively prevents the release of cytochrome c during apoptosis. Cell Death Differ 14, 1086-1094.

Feoktistova, M., Geserick, P., Kellert, B., Dimitrova, D.P., Langlais, C., Hupe, M., Cain, K., MacFarlane, M., Hacker, G., and Leverkus, M. (2011). clAPs block Ripoptosome formation, a RIP1/caspase-8 containing intracellular cell death complex differentially regulated by cFLIP isoforms. Mol Cell 43, 449-463.

Fortes, G.B., Alves, L.S., de Oliveira, R., Dutra, F.F., Rodrigues, D., Fernandez, P.L., Souto-Padron, T., De Rosa, M.J., Kelliher, M., Golenbock, D., et al. (2012). Heme induces programmed necrosis on macrophages through autocrine TNF and ROS production. Blood 119, 2368-2375.

Frank, S., Gaume, B., Bergmann-Leitner, E.S., Leitner, W.W., Robert, E.G., Catez, F., Smith, C.L., and Youle, R.J. (2001). The role of dynamin-related protein 1 , a mediator of mitochondrial fission, in apoptosis. Dev Cell 1, 515-525.

Galluzzi, L., Kepp, O., and Kroemer, G. (2011). FADD: an endogenous inhibitor of RIP3-driven regulated necrosis. Cell Res 21, 1383-1385.

Galluzzi, L., Vitale, I., Abrams, J.M., Alnemri, E.S., Baehrecke, E.H., Blagosklonny, M.V., Dawson, T.M., Dawson, V.L., El-Deiry, W.S., Fulda, S., et al. (2012). Molecular definitions of cell death subroutines: recommendations of the Nomenclature Committee on Cell Death 2012. Cell Death Differ 19, 107-120.

Germain, M., Mathai, J.P., McBride, H.M., and Shore, G.C. (2005). Endoplasmic reticulum BIK initiates DRP1-regulated remodelling of mitochondrial cristae during apoptosis. EMBO J 24, 1546-1556.

Gunther, C., Martini, E., Wittkopf, N., Amann, K., Weigmann, B., Neumann, H., Waldner, M.J., Hedrick, S.M., Tenzer, S., Neurath, M.F., et al. (2011). Caspase-8 regulates TNF-alpha-induced epithelial necroptosis and terminal ileitis. Nature 477, 335-339. 
Haas, T.L., Emmerich, C.H., Gerlach, B., Schmukle, A.C., Cordier, S.M., Rieser, E., Feltham, R., Vince, J., Warnken, U., Wenger, T., et al. (2009). Recruitment of the linear ubiquitin chain assembly complex stabilizes the TNF-R1 signaling complex and is required for TNF-mediated gene induction. Mol Cell 36, 831-844.

Han, J., Zhong, C.Q., and Zhang, D.W. (2011). Programmed necrosis: backup to and competitor with apoptosis in the immune system. Nat Immunol 12, 1143-1149.

Han, W., Xie, J., Li, L., Liu, Z., and Hu, X. (2009). Necrostatin-1 reverts shikonin-induced necroptosis to apoptosis. Apoptosis 14 , 674-686.

Harper, N., Hughes, M., MacFarlane, M., and Cohen, G.M. (2003). Fas-associated death domain protein and caspase- 8 are not recruited to the tumor necrosis factor receptor 1 signaling complex during tumor necrosis factor-induced apoptosis. J Biol Chem 278, 25534-25541.

He, S., Wang, L., Miao, L., Wang, T., Du, F., Zhao, L., and Wang, X. (2009). Receptor interacting protein kinase-3 determines cellular necrotic response to TNF-alpha. Cell 137, 1100-1111.

Holler, N., Zaru, R., Micheau, O., Thome, M., Attinger, A., Valitutti, S., Bodmer, J.L., Schneider, P., Seed, B., and Tschopp, J. (2000). Fas triggers an alternative, caspase-8-independent cell death pathway using the kinase RIP as effector molecule. Nat Immunol 1, 489-495.

Irrinki, K.M., Mallilankaraman, K., Thapa, R.J., Chandramoorthy, H.C., Smith, F.J., Jog, N.R., Gandhirajan, R.K., Kelsen, S.G., Houser, S.R., May, M.J., et al. (2011). Requirement of FADD, NEMO, and BAX/BAK for aberrant mitochondrial function in tumor necrosis factor alpha-induced necrosis. Mol Cell Biol 31, 3745-3758.

Ishii, K.J., Kawagoe, T., Koyama, S., Matsui, K., Kumar, H., Kawai, T., Uematsu, S., Takeuchi, O., Takeshita, F., Coban, C., et al. (2008). TANK-binding kinase-1 delineates innate and adaptive immune responses to DNA vaccines. Nature 451, 725-729.

Jouan-Lanhouet, S., Arshad, M.I., Piquet-Pellorce, C., Martin-Chouly, C., Le Moigne-Muller, G., Van Herreweghe, F., Takahashi, N., Sergent, O., Lagadic-Gossmann, D., Vandenabeele, P., et al. (2012). TRAIL induces necroptosis involving RIPK1/RIPK3-dependent PARP-1 activation. Cell Death Differ. (In Press).

Kaiser, W.J., Upton, J.W., Long, A.B., Livingston-Rosanoff, D., Daley-Bauer, L.P., Hakem, R., Caspary, T., and Mocarski, E.S. (2011). RIP3 mediates the embryonic lethality of caspase-8-deficient mice. Nature 471, 368-372.

Kroemer, G., Dallaporta, B., and Resche-Rigon, M. (1998). The mitochondrial death/life regulator in apoptosis and necrosis. Annu Rev Physiol 60, 619-642.

Laster, S.M., Wood, J.G., and Gooding, L.R. (1988). Tumor necrosis factor can induce both apoptic and necrotic forms of cell lysis. J Immunol 141, 2629-2634.

Lee, Y.J., Jeong, S.Y., Karbowski, M., Smith, C.L., and Youle, R.J. (2004). Roles of the mammalian mitochondrial fission and fusion mediators Fis1, Drp1, and Opa1 in apoptosis. Mol Biol Cell 15, 5001-5011.

Li, J., McQuade, T., Siemer, A.B., Napetschnig, J., Moriwaki, K., Hsiao, Y.S., Damko, E., Moquin, D., Walz, T., McDermott, A., et al. (2012). The RIP1/RIP3 Necrosome Forms a Functional Amyloid Signaling Complex Required for Programmed Necrosis. Cell 150,
339-350.

Liedtke, C., Bangen, J.M., Freimuth, J., Beraza, N., Lambertz, D., Cubero, F.J., Hatting, M., Karlmark, K.R., Streetz, K.L., Krombach, G.A., et al. (2011). Loss of caspase-8 protects mice against inflammation-related hepatocarcinogenesis but induces non-apoptotic liver injury. Gastroenterology 141, 2176-2187.

Meilhac, O., Escargueil-Blanc, I., Thiers, J.C., Salvayre, R., and Negre-Salvayre, A. (1999). Bcl-2 alters the balance between apoptosis and necrosis, but does not prevent cell death induced by oxidized low density lipoproteins. FASEB J 13, 485-494.

Meurette, O., Rebillard, A., Huc, L., Le Moigne, G., Merino, D., Micheau, O., Lagadic-Gossmann, D., and Dimanche-Boitrel, M.T. (2007). TRAIL induces receptor-interacting protein 1-dependent and caspase-dependent necrosis-like cell death under acidic extracellular conditions. Cancer Res 67, 218-226.

Micheau, O., and Tschopp, J. (2003). Induction of TNF receptor I-mediated apoptosis via two sequential signaling complexes. Cell 114, 181-190.

Nakagawa, T., Shimizu, S., Watanabe, T., Yamaguchi, O., Otsu, K., Yamagata, H., Inohara, H., Kubo, T., and Tsujimoto, Y. (2005). Cyclophilin D-dependent mitochondrial permeability transition regulates some necrotic but not apoptotic cell death. Nature 434, 652-658.

Northington, F.J., Chavez-Valdez, R., Graham, E.M., Razdan, S., Gauda, E.B., and Martin, L.J. (2011). Necrostatin decreases oxidative damage, inflammation, and injury after neonatal HI. J Cereb Blood Flow Metab 31, 178-189.

O'Donnell, M.A., Perez-Jimenez, E., Oberst, A., Ng, A., Massoumi, R., Xavier, R., Green, D.R., and Ting, A.T. (2011). Caspase 8 inhibits programmed necrosis by processing CYLD. Nat Cell Biol 13, 1437-1442.

Oberst, A., Dillon, C.P., Weinlich, R., McCormick, L.L., Fitzgerald, P., Pop, C., Hakem, R., Salvesen, G.S., and Green, D.R. (2011). Catalytic activity of the caspase-8-FLIP(L) complex inhibits RIPK3-dependent necrosis. Nature 471, 363-367.

Oerlemans, M.I., Liu, J., Arslan, F., den Ouden, K., van Middelaar, B.J., Doevendans, P.A., and Sluijter, J.P. (2012). Inhibition of RIP1-dependent necrosis prevents adverse cardiac remodeling after myocardial ischemia-reperfusion in vivo. Basic Res Cardiol 107, 270.

Parone, P.A., James, D.I., Da Cruz, S., Mattenberger, Y., Donze, O., Barja, F., and Martinou, J.C. (2006). Inhibiting the mitochondrial fission machinery does not prevent Bax/Bak-dependent apoptosis. Mol Cell Biol 26, 7397-7408.

Petit, F., Arnoult, D., Lelievre, J.D., Moutouh-de Parseval, L., Hance, A.J., Schneider, P., Corbeil, J., Ameisen, J.C., and Estaquier, J. (2002). Productive HIV-1 infection of primary CD4+ T cells induces mitochondrial membrane permeabilization leading to a caspase-independent cell death. J Biol Chem 277, 1477-1487.

Robinson, N., McComb, S., Mulligan, R., Dudani, R., Krishnan, L., and Sad, S. (2012). Type I interferon induces necroptosis in macrophages during infection with Salmonella enterica serovar Typhimurium. Nat Immunol. (In Press).

Salmena, L., and Hakem, R. (2005). Caspase-8 deficiency in T cells leads to a lethal lymphoinfiltrative immune disorder. J Exp Med 202, 727-732.

Sheridan, C., Delivani, P., Cullen, S.P., and Martin, S.J. (2008). Bax- 
or Bak-induced mitochondrial fission can be uncoupled from cytochrome C release. Mol Cell 31, 570-585.

Shulga, N., and Pastorino, J.G. (2012). GRIM-19 Mediated Translocation of STAT3 to Mitochondria is Necessary for TNF Induced Necroptosis. J Cell Sci. (In Press).

Smith, C.C., Davidson, S.M., Lim, S.Y., Simpkin, J.C., Hothersall, J.S., and Yellon, D.M. (2007). Necrostatin: a potentially novel cardioprotective agent? Cardiovasc Drugs Ther 21, 227-233.

Sun, L., Wang, H., Wang, Z., He, S., Chen, S., Liao, D., Wang, L., Yan, J., Liu, W., Lei, X., et al. (2012). Mixed lineage kinase domain-like protein mediates necrosis signaling downstream of RIP3 kinase. Cell 148, 213-227.

Takaoka, A., Wang, Z., Choi, M.K., Yanai, H., Negishi, H., Ban, T., Lu, Y., Miyagishi, M., Kodama, T., Honda, K., et al. (2007). DAI (DLM-1/ZBP1) is a cytosolic DNA sensor and an activator of innate immune response. Nature 448, 501-505.

Takeda, K., Komuro, Y., Hayakawa, T., Oguchi, H., Ishida, Y., Murakami, S., Noguchi, T., Kinoshita, H., Sekine, Y., lemura, S., et al. (2009). Mitochondrial phosphoglycerate mutase 5 uses alternate catalytic activity as a protein serine/threonine phosphatase to activate ASK1. Proc Natl Acad Sci U S A 106, 12301-12305.

Tenev, T., Bianchi, K., Darding, M., Broemer, M., Langlais, C., Wallberg, F., Zachariou, A., Lopez, J., MacFarlane, M., Cain, K., et al. (2011). The Ripoptosome, a signaling platform that assembles in response to genotoxic stress and loss of IAPs. Mol Cell 43, 432-448.

Trichonas, G., Murakami, Y., Thanos, A., Morizane, Y., Kayama, M., Debouck, C.M., Hisatomi, T., Miller, J.W., and Vavvas, D.G. (2010). Receptor interacting protein kinases mediate retinal detachmentinduced photoreceptor necrosis and compensate for inhibition of apoptosis. Proc Natl Acad Sci U S A 107, 21695-21700.

Tsujimoto, Y., and Shimizu, S. (2007). Role of the mitochondrial membrane permeability transition in cell death. Apoptosis 12, 835-840.

Tsujimoto, Y., Shimizu, S., Eguchi, Y., Kamiike, W., and Matsuda, H. (1997). Bcl-2 and Bcl-xL block apoptosis as well as necrosis: possible involvement of common mediators in apoptotic and necrotic signal transduction pathways. Leukemia 11 Suppl 3, 380-382.

Upton, J.W., Kaiser, W.J., and Mocarski, E.S. (2010). Virus inhibition of RIP3-dependent necrosis. Cell Host Microbe 7, 302-313.

Upton, J.W., Kaiser, W.J., and Mocarski, E.S. (2012). DAI/ZBP1/DLM-1 complexes with RIP3 to mediate virus-induced programmed necrosis that is targeted by murine cytomegalovirus vIRA. Cell Host Microbe 11, 290-297.

Vandenabeele, P., Galluzzi, L., Vanden Berghe, T., and Kroemer, G. (2010). Molecular mechanisms of necroptosis: an ordered cellular explosion. Nat Rev Mol Cell Biol 11, 700-714.

Vanlangenakker, N., Bertrand, M.J., Bogaert, P., Vandenabeele, P., and Vanden Berghe, T. (2011a). TNF-induced necroptosis in L929 cells is tightly regulated by multiple TNFR1 complex I and II members. Cell Death Dis 2, e230.

Vanlangenakker, N., Vanden Berghe, T., Bogaert, P., Laukens, B., Zobel, K., Deshayes, K., Vucic, D., Fulda, S., Vandenabeele, P., and Bertrand, M.J. (2011b). clAP1 and TAK1 protect cells from TNF-induced necrosis by preventing RIP1/RIP3-dependent reactive oxygen species production. Cell Death Differ 18, 656-665.

Vanlangenakker, N., Vanden Berghe, T., and Vandenabeele, P. (2012). Many stimuli pull the necrotic trigger, an overview. Cell Death Differ 19, 75-86.

Vercammen, D., Beyaert, R., Denecker, G., Goossens, V., Van Loo, G., Declercq, W., Grooten, J., Fiers, W., and Vandenabeele, P. (1998a). Inhibition of caspases increases the sensitivity of L929 cells to necrosis mediated by tumor necrosis factor. J Exp Med 187, 1477-1485.

Vercammen, D., Brouckaert, G., Denecker, G., Van de Craen, M., Declercq, W., Fiers, W., and Vandenabeele, P. (1998b). Dual signaling of the Fas receptor: initiation of both apoptotic and necrotic cell death pathways. J Exp Med 188, 919-930.

Wang, L., Du, F., and Wang, X. (2008). TNF-alpha induces two distinct caspase-8 activation pathways. Cell 133, 693-703.

Wang, Z., Jiang, H., Chen, S., Du, F., and Wang, X. (2012). The mitochondrial phosphatase PGAM5 functions at the convergence point of multiple necrotic death pathways. Cell 148, 228-243.

Welz, P.S., Wullaert, A., Vlantis, K., Kondylis, V., Fernandez-Majada, V., Ermolaeva, M., Kirsch, P., Sterner-Kock, A., van Loo, G., and Pasparakis, M. (2011). FADD prevents RIP3-mediated epithelial cell necrosis and chronic intestinal inflammation. Nature 477, 330-334.

Wright, A., Reiley, W.W., Chang, M., Jin, W., Lee, A.J., Zhang, M., and Sun, S.C. (2007). Regulation of early wave of germ cell apoptosis and spermatogenesis by deubiquitinating enzyme CYLD. Dev Cell 13, 705-716.

Wu, C.J., Conze, D.B., Li, T., Srinivasula, S.M., and Ashwell, J.D. (2006). Sensing of Lys 63-linked polyubiquitination by NEMO is a key event in NF-kappaB activation [corrected]. Nat Cell Biol 8, 398-406.

Zhang, D.W., Shao, J., Lin, J., Zhang, N., Lu, B.J., Lin, S.C., Dong, M.Q., and Han, J. (2009). RIP3, an energy metabolism regulator that switches TNF-induced cell death from apoptosis to necrosis. Science 325, 332-336.

Zhang, H., Zhou, X., McQuade, T., Li, J., Chan, F.K., and Zhang, J. (2011). Functional complementation between FADD and RIP1 in embryos and lymphocytes. Nature 471, 373-376.

Zhao, J., Jitkaew, S., Cai, Z., Choksi, S., Li, Q., Luo, J., and Liu, Z.G. (2012). Mixed lineage kinase domain-like is a key receptor interacting protein 3 downstream component of TNF-induced necrosis. Proc Natl Acad Sci U S A 109, 5322-5327. 